\title{
CONFLUÊNCIAS ENTRE MARGENS E ESPACIALIDADES EM LUCIANO SERAFIM E GUIMARÃES ROSA
}

\section{CONFLUENCES BETWEEN MARGINS AND SPATIALITIES IN LUCIANO SERAFIM AND GUIMARÃES ROSA}

\author{
Cristian de Oliveira Lopes ${ }^{1}$ \\ Debora Pereira Simões ${ }^{2}$
}

\begin{abstract}
RESUMO
O artigo, de natureza comparatista, propõe-se a refletir acerca das noções de espaço e fronteira, nos contos "A outra margem", de Luciano Serafim (2003), e "A terceira margem do rio", de Guimarães Rosa (2001). Para tal, elucidaremos a própria ideia de "margem", a fim de perceber como esta noção se configura a partir dos lugares de enunciação dos objetos em estudo. Baseado numa perspectiva da crítica cultural latino-americana, o artigo busca evidenciar os aspectos de regionalismo crítico e identidade cultural na literatura produzida no Mato Grosso do Sul, tomando como aporte teórico, especialmente, os estudos sobre região desenvolvidos por Bourdieu (1989), bem como as importantes contribuições de Kaliman (1994), Santiago (2000) e Santos $(2008,2009)$, acerca do regional e dos estudos culturais. Posterior e finalmente, faz-se uma leitura contrastiva das "margens" (enquanto conceito e tal qual se apresentam nas narrativas), adotando um enfoque dos estudos fenomenológicos de Bachelard (1997; 2008) para lançar luz às espacialidades representadas nos contos e as respectivas enunciações destes lugares.
\end{abstract}

PALAVRAS-CHAVE: Luciano Serafim; Guimarães Rosa; crítica cultural. 


\section{ABSTRACT}

The article, of comparative nature, reflects on the notions of space and frontier, in the short stories "A outra margem", by Luciano Serafim (2003), and "A terceira margem do rio", by Guimarães Rosa (2001). Thus we will elucidate the very idea of "margin", in order to perceive how this notion is configured from the places of enunciation of the objects under study. Based on a perspective of latin american cultural critique, the article seeks to highlight the aspects of critical regionalism and cultural identity in the literature produced in Mato Grosso do Sul, taking as a theoretical contribution especially the studies as to region developed by Bourdieu (1989), as well as the important contributions of Kaliman (1994), Santiago (2000) and Santos $(2008,2009)$ about regional and cultural studies. Later and finally, a contrastive reading of the "margins" (as a concept and as presented in the narratives), adopting a focus of Bachelard's phenomenological studies $(1997,2008)$ to shed light on the spatialities represented in the stories and the respective enunciations of these places.

KEYWORDS: Luciano Serafim; Guimarães Rosa; cultural critique.

\section{INTRODUÇÃO}

Considerando a fortuna teórico-crítica acerca do regionalismo brasileiro e a complexidade dos variados temas sobre os quais ela se debruça, este texto visa a destacar, no cruzamento dos contos "A outra margem", de Luciano Serafim (2003) e "A terceira margem do rio", de João Guimarães Rosa ([1962]; 2001), noções acerca de fronteiras e margens, estendendo-se ao espaço enquanto referência textual e lugar de enunciação dos respectivos autores.

Refletir acerca dos aspectos regionais, a partir de temas comuns a estas narrativas, faz-se necessário para elucidar, num primeiro momento, uma reflexão acerca das nuances de regionalismo e identidade cultural na literatura produzida no Mato Grosso do Sul, tomando como aporte teórico, especialmente, os estudos sobre região desenvolvidos por Bourdieu (1989), bem como as contribuições de Kaliman (1994), Santiago (2000) e Santos (2008; 2009), acerca do regional e da crítica cultural latino-americana. No segundo e no terceiro tópicos, à luz do regionalismo, da crítica cultural e dos estudos fenomenológicos de Bachelard (1997; 2008), pretende-se, por meio de uma análise teórico-crítica, lançar luz às espacialidades representadas pelas margens.

Este recorte teórico justifica-se por nos propiciar um maior aprofundamento na discussão sobre como a literatura sul-mato-grossense, com enfoque no escritor Luciano Serafim, se configura no regionalismo brasileiro e/ou como o regional prefigura ${ }^{3}$ na literatura do Mato Grosso do Sul, para a partir daí, adentrarmos nos nossos objetos de análise. 
Interessa-nos também, precisar o papel do escritor sul-mato-grossense num contexto regional, situando-o, desse modo, numa região de fronteiras culturais que se diluem e se contrastam, seja no espaço local, seja no contexto latino-americano, configurando-se numa espécie de "entre-lugar"4 em que o escritor e a literatura ainda são marginalizados em relação ao centro, à metrópole, à literatura nacional e, mais amplamente, àquela produzida no hemisfério norte. Daí a importância de críticos e teóricos como o uruguaio Hugo Achugar, que, em sua obra, Planetas sem boca (2006), faz questão de enfatizar que o nosso Norte é o Sul, tal qual o argentino Walter Mignolo $(2003)^{5}$, que destaca-se entre os mais renomados intelectuais latino-americanos, cuja obra cunha conceitos como "Pensamento liminar", "Epistemologia das margens", "Gnose liminar", etc., a fim de traçar uma genealogia do pensamento pelo qual histórias locais absorvem e coexistem com projetos globais, de modo a enaltecer a produção artística, cultural e intelectual da América Latina.

A proposta de realização deste estudo conflui nessas correntes. Inicialmente, a partir do nosso particular interesse pela crítica cultural, pelos estudos pós-coloniais e, de igual modo, pelas textualidades do escritor e poeta Luciano Serafim, as quais merecem ser acessadas e lidas. Suas obras vêm ganhando destaque na literatura sul-mato-grossense; constituem objeto de pesquisas e são debatidas em eventos acadêmicos regionais e nacionais. Daí a ideia de estabelecer um paralelo com Guimarães Rosa, autor canônico e reconhecido internacionalmente.

\section{CONSIDERAÇÕES SEMÂNTICAS}

O conceito de região abriga análises variadas e que confundem uma apreensão definitiva do termo. A Geografia, a exemplo disto, define região como um espaço demarcado por fronteiras, quer separadas por linhas ou não. Bourdieu (1989) vai além ao atestar que "a região é o que está em jogo como objeto de lutas entre os cientistas” (Bourdieu, 1989, p. 108).

No plano simbólico, a região é um espaço à margem, periférico em relação ao centro, isso vale para o Mato Grosso do Sul, lugar de onde se escreve e lugar-tema sobre o que se escreve, o qual ainda que se localize no centro-oeste do país, é uma região periférica, à margem, especialmente no que se refere à produção literária. Nessa perspectiva, o termo "região" não define apenas um espaço geográfico, uma realidade natural, mas uma divisão sócio-espacial estabelecida, sobretudo, por relações de poder. Mas, mais profundamente, o sociólogo ressalta que

A etimologia da palavra região (regio) [...] conduz ao princípio da di-visão, acto mágico, quer dizer, propriamente social, de diacrisis que introduz por decreto uma descontinuidade decisória na continuidade natural (não só entre as regiões do espaço, mas também entre as idades, os sexos, etc.). Regere fines, o acto que consiste em "traçar as fronteiras em linhas rectas", em separar o interior do exterior [...]. (Bourdieu, p. 113-114; grifos do autor). 
Como contraponto a esta região 'natural', contornada por fronteiras que separam o território regional do nacional, bem como separam território nacional do estrangeiro, Ricardo Kaliman nos apresenta uma percepção que, em certa medida, destoa em relação a definição de Bourdieu, podendo vir a ressemantizar o entendimento sobre região descrito por ele anteriormente. A saber:

[...] uma região não é, na sua origem, uma realidade natural, mas uma divisão do mundo estabelecida por um ato de vontade [...]. A região deixa de ser um espaço natural, com fronteiras naturais, pois é, antes de tudo, um espaço construído por decisão arbitrária, política, social, econômica, ou de outra ordem qualquer que não, necessariamente, cultural e literária. (Kaliman apud Santos, 2009, p. 79).

Por esta perspectiva, entendemos a região não (tão somente) como espaço geográfico e natural, com fronteiras demarcatórias, mas como um lugar construído por ordens outras. Isso nos remete a pensar o Mato Grosso do Sul enquanto região situada numa espécie de "entre-lugar", simultaneamente centralizado e periférico. Região fronteiriça em que o sujeito tem, desde cedo, o seu ethos6 construído com influências da língua estrangeira (que na junção das duas já não lhe é tão estranha), dos dialetos e da cultura do outro que está logo ali, à outra margem, movimentando, assim, no plano representativo do real, o contrabando de ideologias, crenças e tradições, de modo a enriquecer significativamente ambas as regiões (culturais).

Nesse sentido, de acordo Edgar Cézar Nolasco (2009), "Na infância do lugar-regional [...] o sujeito fala a sua voz ininteligível para o outro. Esse lugar, que me escolheu e que foi escolhido por mim, marca meu corpo, minha história, com suas faltas, suas carências, com seu próprio corpo". (Nolasco, 2009, p. 102). Além dessa identificação do sujeito com a sua região (seu local de origem, seu lugar de fala), comum em romances e contos regionalistas, faz-se necessário trazer à discussão essa "voz ininteligível” do sujeito, e, aqui, chama-se a atenção para o caso do escritor sul-mato-grossense, que fala de um lugar multicultural, miscigenado, cujo locus enunciativo coexiste entre o particular e o universal.

Este locus, justifica a esse indivíduo ser representado pelo entre-lugar, quer seja pela localização geográfica, concomitantemente, centralizada e fronteiriça, quer seja pelo sujeito muitas vezes "sem-voz", ainda marginalizado e que anseia ser ouvido, cá, dos "deslimites do vazio" que configuram o MS. Seguindo este raciocínio, conforme aponta Bourdieu,

o discurso regionalista, é um discurso performativo, que tem em vista, impor como legítima uma nova definição das fronteiras e dar a conhecer e fazer reconhecer a região assim delimitada - e, como tal, desconhecida - contra a definição dominante (Bourdieu, 1989, p. 116).

Ele afirma ainda que "se a região não existisse como espaço estigmatizado, [...] não teria que reivindicar a existência” (Bourdieu, 1989, p. 126). Entende-se, assim, que o que sustentaria por conceito de região, mais 
que as mistificações geográficas, é, por vezes, o jogo de lutas e os interesses políticos. Em certa medida, isso justifica o anseio em ser ouvido, por parte do escritor e a resistente permanência da literatura do Estado.

Sob o mesmo ponto de vista, com Paulo Nolasco dos Santos (2009), tem-se, da perspectiva dos estudos literários, um contraponto em que se percebe aproximações e distanciamentos do que atesta Bourdieu acerca do "discurso regionalista":

O regionalismo, por si só, é duplamente entendido com a busca da identidade brasileira através do específico regional e como representação literária de uma determinada região do país, e, ainda se a distinção entre o regionalismo e a literatura regional/sistema literário regional deve ser preservada pela alusão e semantização de 'conteúdos' específicos, além de agenciar gêneros e/ou formas diferentes, bem assim a proposta de caracterização de uma 'região cultural' parece justificar-se de modo especial quando se consideram os cruzamentos entre mais de um território nacional - como é o caso da questão aqui apontada e formulada como problema, a região cultural do extremo oeste do Brasil, no Centro-Sul do estado de Mato Grosso do Sul. A caracterização de uma região cultural específica, marcada pelas relações de troca, transferências e traduções de outras regiões, essas também caracterizadas por regionalismos outros, procuraria explicar as relações - trocas-transferências - entre o próprio e o alheio e o entrecruzamento de uma região a outra (Santos, 2009, p. 79).

Dois pontos saltam aos olhos. O primeiro, consoante com Bourdieu, quando permite o entendimento do regionalismo como a busca da identidade, brasileira ou não, através de uma região em especial. O segundo, quando se refere à "região cultural", caracterizada, também, pelo cruzamento de mais de um território nacional, como o Centro-Sul do estado de Mato Grosso do Sul. Este último ponto nos interessa, por se referir ao lugar de onde escreve Luciano Serafim, nome importante da literatura nessa região cultural, que apresentaremos e o tomaremos como mote deste estudo.

Nesta esteira de pensamento, ainda com Santos (2008), retomando o verso de Manoel de Barros, o "vazio" mencionado pelo poeta é relacionado com a região do MS, extremo Oeste do Brasil:

O "vazio" aludido [no verso de Manoel de Barros] pode ser lido, neste caso como expressão de um imaginário resistente ao preenchimento e à lacuna, fruto de um senso comum que nos habituou a ver, aqui no Centro-Sul do estado e no extremo Oeste do Brasil, mais a ausência, mais a distância dos grandes centros do que as próprias potencialidades da região. (Santos, 2008, p. 16). 
Essa ausência, esse distanciamento em relação aos grandes centros, mencionada pelo regionalista, é confluente com o pensamento de Kaliman (1994) ao afirmar que

cuanto más lejos del centro se produzca um texto, menos possibilidades tendrá de acceder al canon. Esto es así porque para aceder al merecimiento de los estudios literários, um texto de la periferia debía sujetarse a las condiciones fijadas por el centro. (Quanto mais longe do centro é produzido um texto, menor será a chance de acessar o cânone. Isto é assim porque, para alcançar o mérito dos estudos literários, um texto da periferia tem que sujeitar-se às condições fixadas pelo centro). (Kaliman, 1994, p. 12; tradução nossa).

O centro, enquanto controlador da difusão e prestígio dos textos, fixa as condições para que determinada obra seja minimamente merecedora de reconhecimento.

O que vale para a América Latina em relação à Europa (local x global), vale também para o Centro-Sul do estado do MS em relação ao país (regional x nacional), bem como em relação ao nordeste - à uma literatura regional já bem estabelecida, a exemplo à de João Guimarães Rosa. Sobre o termo 'regional'7, entende-se, ora em oposição a 'nacional', ora em oposição a 'universal'. Isto se dá por um conjunto de relações que apontam para esse significado, seja com base em critérios geográficos, ecológicos, culturais ou com base em relações de poder.

Diante desta reflexão, Kaliman afirma que "la literatura regional sería aquella producida por autores que escriben em certa región y hablan de esa misma región" ("a literatura regional seria a produzida por autores que escrevem em certa região e falam desta mesma região"). (Kaliman, 1994, p. 8; tradução nossa). Está-se, portanto, a falar de uma nuance bastante específica da literatura, qual seja, o 'apego ao próprio chão'. Trata-se de expressões literárias cujo foco volta-se para a representação da 'cor local', contemplando aspectos geográficos, históricos, sociais e as peculiaridades da linguagem de onde se fala.

Saliente-se a literatura de Guimarães Rosa (2001), ambientada no sertão nordestino, caracterizada por seu apego ao regional, aos personagens típicos da sua região, à linguagem a serviço da temática regionalista proposta em seus contos e romances. Assim, sua obra ${ }^{8}$ ainda se configura num desafio não só para a crítica literária, como para diversos outros campos do conhecimento, haja vista o seu caráter multidisciplinar.

Com efeito, propõe-se um estudo comparativo com base nos contos "A outra margem", de Luciano Serafim e "A terceira margem do rio", de Guimarães Rosa, a fim de contrastar e/ou aproximar os respectivos regionalismos - o do sertão nordestino e o sul-mato-grossense -, bem como explorar as espacialidades possíveis destas regiões físicas e culturais, a partir das nas narrativas. A começar pela serafiniana. 


\section{O ESPAÇO COMO LUGAR DE ENUNCIAÇÃO LITERÁRIA EM "A OUTRA MARGEM"}

“A outra margem" intitula o conto de Luciano Serafim (2003), do qual se propõe apresentar uma leitura sob a luz do regionalismo sul-mato-grossense e da crítica cultural latino-americana, a fim de evidenciar temas e/ou conceitos, como margem, fronteira e espaço - presentes nas tramas do texto. Tais temas justificam-se por serem comuns a esta região geográfico-cultural de onde fala o escritor.

Estes conceitos sugerem um outro modo de olhar para o ambiente (enquanto elemento da ficção), local em que ocorrem os acontecimentos, particularmente, em narrativas desse tipo, produzidas na contemporaneidade. No entanto, antes de prosseguir nesta reflexão, faz-se importante abrir parênteses para uma breve contextualização do autor e sua produção literária.

Nascido em Maceió - AL, no dia 2 de maio de 1977, Luciano Serafim viveu até a adolescência entre Fleixeiras e Messias, zona da mata alagoana. Reside em Dourados - MS desde 1994, onde formou-se em Letras pela Universidade Federal da Grande Dourados (UFGD) e publicou os livros: Eu, entre nós (2002), livro de poemas patrocinado pelo Fundo de Investimentos Culturais (FIC), da Fundação de Cultura de Mato Grosso do Sul; HQs Medos (2003), ilustrada por Eugenio Colonnesi, pela Editora Escala; Outro dia a gente sai (livro de contos, 2003); publicou, também, contos na revista Fórum Xanadu (2003), da Editora Gênero; produziu roteiros para HQs, publicados na revista Hentai X (2003), da Editora Gênero; Organizou, juntamente com Carlos Magno Mieres Amarilha e Nicanor Coelho, o livro Patrimônio Cultural de Mato Grosso do Sul: Identidades e Memórias (2007); Mordendo as lábias (livro de poemas, 2008); Curumim de asfalto (livro infanto-juvenil, 2009); Raiz transeunte (livro de poemas, 2013); e, Sururu com Coca-Cola (livro de poemas, 2016). Seu currículo se estende como integrante do Grupo Literário Arandu e co-fundador do Arrebol Coletivo Literário ${ }^{9}$, onde desenvolve projeto de publicação de livros artesanais, lançando jovens escritores da região.

Fechando os parênteses, o conto serafiniano, aqui agenciado, narra as ações de um sujeito à margem do rio Mundaú ${ }^{\boxplus}$, o qual está observando fauna e flora ao seu redor, oscilando entre momentos de calmaria, de inquietude e de angústia, por razões, até então, desconhecidas. O narrador consegue descrever com maestria a natureza belíssima como pano de fundo situacional: o entorno do rio arborizado de cajueiros, o cardume de peixes, o barranco arenoso e as "andorinhas brincalhonas" banhando-se em meio à tarde.

Nesse ponto do texto, percebe-se uma "atitude contemplativa", para utilizar a expressão usada por Gaston Bachelard, ao tratar dos agentes de imensidão que se configuram num "olhar tranquilo", numa "paz [que] institui-se como uma emergência do ser, como um valor que domina ape- 
sar dos estados subalternos do ser, apesar de um mundo conturbado" (Barchelard, 2008, p. 2014). No entanto, se ouvirmos "a voz das águas", como sugerem os versos de Caetano Veloso e Milton Nascimento; se olharmos da perspectiva deste homem à margem, como se mergulharmos nas profundezas do Mundaú, teremos a nítida percepção de que estas imagens, descritas pelo narrador até o segundo parágrafo do texto, não são tão transparentes como parecem. Há uma certa obscuridade que envolve este personagem nesta cena, há um efeito sombrio nesta trama, como se nota no seguinte trecho:

Calmamente, espetou uma gorda minhoca no anzol. Jogou a linha na água. Alguns pingos frescos o molharam. Sentiu uma estranha sensação de limpeza. Engraçado... Limpo? Ele, que há menos de meia hora havia sujado para sempre o próprio caráter? Seu olhar mortiço vagou ansioso, mas lentamente, para a outra margem. A areia alva (como deve ser a da praia) já não mostrava suas pegadas. O vento as apagara. [...] Os pingos que agora o molharam fizeram com que se sentisse sujo. Mas não era ele que estava sujo... Era a água! Toda a água daquele rio! Águas sujas de sangue, águas mortíficas! (Serafim, 2003, p. 43).

Percebe-se neste fragmento, com Bachelard, por um lado a "dialética da imensidão e da profundidade" tanto na "hipérbole do olho que vê demais [quanto na] hipérbole da paisagem que se vê confusamente sob as pesadas pálpebras de suas águas adormecidas" (Bachelard, 2008, p. 213). Por outro, "simpatizamos obscuramente com o drama da pureza e da impureza da água. Quem não sente, por exemplo, uma repugnância especial, irracional, inconsciente, direta pelo rio sujo?" (Bachelard, 1997, p. 143). Em meio a estas reflexões acerca do cenário e da personagem, há que se destacar o rio, cujas águas, juntamente com "a maré de sangue que seguiu o cadáver de sua mulher [referência à companheira da personagem] rumo ao oceano" (Serafim, 2003, p. 43), representam a fronteira, a terceira margem - sangue, água e corpo.

Gaston Bachelard (1997; 2008), especialmente em A água e os sonhos: ensaio sobre a imaginação da matéria e A poética do espaço, destaca-se entre os principais suportes, aqui selecionados, para a leitura de Luciano Serafim e, posteriormente, de Guimarães Rosa, dada a sua aproximação aos estudos fenomenológicos, os quais não podemos desconsiderar, tendo em vista o caráter dos contos.

"A outra margem" contempla, do ponto de vista da estrutura, da forma e do conteúdo, uma economia característica deste tipo de textualidade. Luciano Serafim consegue lançar mão de uma linguagem simples, com a objetividade peculiar do conto, sem perder, essencialmente, uma de suas maiores forças - a poesia. Falando em sua poesia, pode-se facilmente estabelecer um diálogo entre o texto que ora analisamos e um poema de sua autoria, presente em Raiz Transeunte - transcrevo-o agora: "à beira do 
precipício/ à margem dos escrúpulos/ qualquer semelhança/ não é mera coincidência/ meu sangue é impuro fel" (Serafim, 2013, p. 22). O homem à margem do rio também estava diante de um abismo.

Vale ressaltar que o rio Mundaú, elemento que faz referência ao local da cena, embora não seja um curso d'água natural sul-mato-grossense, mas sim do nordeste brasileiro, isso não desfigura o regionalismo a que a obra pertence - este defendido até aqui -, tampouco a descaracteriza se a pensarmos a partir do locus enunciativo do contista. Este argumento sustenta-se nos pressupostos teóricos de Ricardo Kaliman (1994), quando discorre sobre o espaço de enunciação literária e o espaço como referência do texto.

Hay dos relaciones entre y espacio que circulan todavia afianzadamente em el discurso crítico: 1) hay um lugar donde se escribe, el espacio de enunciación literaria [...]. 2) hay um lugar como tema sobre el que se escribe, el espacio como referencia del texto. (Existem duas relações entre o espaço que ainda circulam fortemente no discurso crítico: 1) há um lugar de onde se escreve, o espaço da enunciação literária [...]. 2) há um lugar como tema sobre o que se escreve, o espaço como referência do texto). (Kaliman, 1994, p. 5; tradução nossa).

Pozenato, por sua vez, realça o que escrevemos sobre o sujeito (escritor) e a literatura produzida por ele nesta região do Centro-Oeste brasileiro, quando atesta o seguinte:

A literatura é resultado de uma feitura: é por isso um fato e é uma obra. Como fato, ela se alinha com todos os fatos que fazem a história; e como obra, é resultado de um fazer individual e social e, assim, um fenômeno de cultura. A história e a cultura são pois suas fronteiras. Demarcar um corpus literário, como a própria palavra demarcação sugere, é trabalhar nas fronteiras, isto é, lidar com fenômenos de um e de outro lado [...]. (Pozenato, 1974, p. 22).

"A outra margem" é resultado deste fenômeno cultural que ocorre no Mato Grosso do Sul, que abriga tanto a memória sócio-histórica do próprio quanto a do alheio configurando nessa literatura produto da rica (inter)cultura que nos pertence. Acrescente-se a isso o fato de Luciano Serafim ser, simbolicamente, uma forma de arquétipo do Mato Grosso do Sul, pois, além de ambos possuírem a mesma idade, o autor representa o elemento nordestino presente na formação da unidade da Federação, permeada que é pela migração de brasileiros vindos do nordeste, do sudeste e do sul do país quando da criação da CAND, pelo ex-presidente Getúlio Vargas, a fim de estimular a fixação do homem à terra e ocupação do solo. Em certa medida, o migrante forma e é formado pelo espaço geográfico-cultural sul-mato-grossense, do mesmo modo em que o autor, mesmo se valendo de um elemento do nordeste para configurar o espaço, preenche-o com uma poeticidade forjada nesse entre-lugar cultural, simbolizado pelo elemento do rio, a fundir o próprio e o alheio. 
Sob essa perspectiva é possível estabelecer interseções nos textos de Eurídice Figueiredo (2013) e Wladimir Krysinski (2005), sobretudo para destacarmos as noções de local e regional, presentes nas reflexões propostas pelos objetos citados, bem como para se pensar a configuração do marginal neste contexto.

Conforme Krysinski, "o marginal é aquele que não tem o reconhecimento do centro. Isto é, do próprio institucional. É o institucional que exclui o marginal do campo de legitimidade e que o isola" (Krysinski, 2005, p. 201). O institucional é, muitas vezes, quem dita as condições de produção do marginal, quer seja pelo sistema editorial, quer seja pelos veículos de comunicação (TV, rádio, internet, etc.), ou ainda através da crítica.

Assim, ciente de que o "marginal" fala do local, do chão onde pisa, vale o diálogo com Figueiredo, não só quando ela trata da universalização do regional, com o exemplo das novelas e dos romances do escritor amazonense Milton Hatoum, como quando ela afirma que

historicamente, houve, na América Latina, a oposição entre regionalismo (geralmente associado ao romance rural) e cosmopolitismo/universal, isso se deve ao fato de se considerar o primeiro enquanto atrasado enquanto o urbano teria caráter universal e seria, portanto, associado ao moderno (ao centro). (Figueiredo, 2013, p. 44).

Krysinski (2005) e Figueiredo (2013) se somam em um esforço de desconstruir uma literatura homogênea, detentora de valores baseados em critérios institucionais, de igual modo descontruir a ideia de que uma literatura deve ser referência por ser canônica ou produzida pelo centro cultural (Europa), ou pelas grandes metrópoles. Haja vista a multiplicidade de autores e obras que se fazem conhecer nos países anteriormente colonizados, nas últimas décadas, quer seja pelas premiações, como Nobel de literatura e premiações nacionais, por exemplo, quer seja pelo número de traduções que determinada obra passa, tornando-se conhecida mundialmente.

Ao pensarmos sobre este locus de enunciação (MS), torna-se evidente com Santos (2008) que a região Centro-Sul do estado, onde está situada a cidade de Dourados, passa ainda hoje por um processo de formação cultural em que o escritor e a literatura estão imersos neste caldeirão, constantemente temperados por ingredientes diversos, composto por elementos locais e globais, resultando, assim, num todo espesso, característico, particular e genuíno. Assim, tem-se neste lugar de cultura um rico universo regional de onde o escritor e a literatura sul-mato-grossense falam ao universo outro, à outra margem. 


\section{O ESPAÇO COMO REFERÊNCIA DO TEXTO NO CONTO "A TERCEIRA MARGEM DO RIO"}

Aquele barco que passou/ lentamente pelo cais/ levou minha tristeza;/ tomara que não volte mais. (Serafim, 2002, p. 14)

O poema que abre este tópico, retirado da obra Eu entre nós (2002), de Luciano Serafim, trata de um estado de ânimo decaído do eu lírico. Uma espécie de melancolia superficial, um sentimento passageiro, como um barco de passagem pelo cais, movendo levemente as águas no seu entorno. Por outro lado, reflete o seu apreço pelo chão local quando faz uma alusão às águas que banham o Mato Grosso do Sul, bem como evidencia, novamente, a margem por meio do "cais", quer sejam as diversas margens dos rios sul-mato-grossenses, quer seja o lugar de quem está de fora, ou ainda, comumente, lugar de embarque e desembarque.

Pensar o "cais" enquanto margem, enquanto lugar de quem olha de fora, possibilita não só olhar para os objetos apresentados anteriormente com um enfoque, como propicia um estudo comparativo entre Serafim (2003) e Guimarães Rosa (2001), o que nos permite explorar as diversas espacialidades representadas nas respectivas obras, a começar pelo conto rosiano.

Antes, em poucas linhas, uma síntese sobre a biografia deste autor, o qual teve "uma infância povoada de bichos, livros e molecagens", conforme aponta Beth Brait (1982, p. 3) ${ }^{11}$. João Guimarães Rosa possui uma vasta fortuna crítica, haja vista a dimensão e profundidade que atingiu sua obra, bem como a sua importância para a literatura universal. Nasce em 1908 em Cordisburgo - MG e passa a residir e estudar em Belo Horizonte dez anos mais tarde. Dentre os diversos momentos importantes da sua vida, vale destacar a sua atuação em Paris como primeiro secretário e conselheiro da embaixada (1950), a sua promoção à diplomacia (1958) e a publicação de Primeiras estórias - livro de contos, dentre os quais evidenciamos "A terceira margem do rio" -, quando assume a Chefia do serviço de demarcação de fronteiras, em 1962.

"A terceira margem do rio" ${ }^{12}$, conto que compõe o livro Primeiras estórias, publicado primeiramente em 1962, retrata uma família de ribeirinhos composta por cinco pessoas: pai, mãe e três filhos (dois homens e uma mulher). A “estória", para usar o termo adotado pelo próprio autor, narrada e protagonizada por um dos filhos homens - o qual permaneceu à margem esperando um encontro que não poderia se dar -, expõe o pai como um homem introspectivo que, num determinado dia, manda fazer uma canoa que pudesse durar aproximadamente trinta anos, a fim de com ela permanecer no rio, numa ida sem volta, como atesta-se na seguinte passagem:

Nosso pai entrou na canoa e desamarrou, pelo remar. E a canoa saiu se indo - a sombra dela por igual, feito um jacaré, comprida longa. [...] Nosso pai não voltou. Ele não tinha ido a nenhuma parte. Só executava a invenção de se permanecer naqueles espaços do rio, de meio a meio, sempre dentro da 
canoa, para dela não saltar nunca mais. [...] As vozes das notícias se dando pelas certas pessoas - passadores, moradores das beiras, até do asfalto da outra banda - descrevendo que nosso pai nunca se surgia a tomar terra, em ponto nem canto, de dia nem de noite, da forma como cursava no rio, solto solitariamente. (Rosa, 2001, p. 67).

Percebe-se neste personagem uma decisão insólita que promove uma série de reflexões, tanto para quem fica à margem do rio, quanto no próprio leitor que passa a se questionar num exercício existencial, acerca de um homem velho, que, por vontade própria, vai para uma espécie de não-lugar, fixo, estável sobre o movimento, situando-se perpétua e estaticamente neste "entre", na fronteira, conforme Carvalhal (1994, p. 95), neste espaço de passagens, "onde algo migra, se reelabora e se refaz" - o rio no seu fluir natural.

Para além das possíveis reflexões existenciais, psicanalíticas e até mesmo narcisistas que o conto, mas, sobretudo, esta personagem, pode suscitar ao se isolar sob a sua introspecção, vendo diuturnamente "a sua própria imagem” (Bachelard, 1998, p. 21) refletida na água, tal qual os problemas universais retratados através do homem do sertão, pretende-se aqui, evidenciar o que se pode denominar de "terceiro lugar", esse espaço flutuante que faz do homem, sua canoa e o rio o "meio", e do "meio", estes três (ser, objeto e elemento).

Jean Chevalier (1986), traz uma definição de água que convém a esta reflexão: qual seja: "a água é o símbolo das energias inconscientes, das potencias informes da alma e das motivações secretas e desconhecidas" (Chevalier, 1986, p. 60) ${ }^{13}$. Em certa medida, esta definição dá luz à complexidade íntima deste personagem, que, no seu isolamento, busca uma aproximação com a água.

Neste sentido, o narrador apresenta seu pai como aquele que está "sempre fazendo ausência". Embora estivesse "perpetuamente" presente, mantendo-se sempre ali com sua canoa no meio do rio, próximo à sua casa, à vista de todos, "não pojava em nenhuma das duas beiras, nem nas ilhas e croas de rio, não pisou mais em chão nem capim” (Rosa, 2001, p. 68). Nas palavras do filho, percebe-se a angústia não só da ausência-presente do pai, mas também do silêncio em resposta às suas questões, como no seguinte trecho: "Sendo que, se ele não se lembrava mais, nem queria saber da gente, por que, então, não subia ou descia o rio, para outras paragens, longe, no não-encontrável? Só ele soubesse” (Rosa, 2001, p. 68). O filho questiona-se e responde a si: "Só ele soubesse". Como se o próprio silêncio ressoasse na sua voz e na de todos que não viam razão em tal feito.

A fenomenologia de Bachelard (1997, p. 21), por um lado, vai justificar dizendo que é "necessária uma alma muito perturbada para realmente se deixar enganar pelas miragens do rio. Esses doces fantasmas da água costumam estar ligados às ilusões factícias de uma imaginação divertida, de uma imaginação que quer divertir-se." No entanto, não parece haver nenhuma perturbação psíquica ou do espírito, no caso específico deste homem. Mas no que tange a uma imaginação que anseia divertir-se, 
Caetano Veloso e Milton Nascimento perceberam este possível lapso de comicidade entre o sujeito e a água nos seguintes versos: "Meio a meio o rio ri/ Silencioso, sério/ Nosso pai não diz, diz"14.

Com efeito, por outra perspectiva, Bachelard (1997) discorre sobre a relação da água com o inconsciente, que este elemento "puro" e "claro" seria "um apelo às poluições". Pois,

Muitas outras páginas poderiam dar assim a prova, pelo absurdo, do valor inconsciente ligado a uma água pura. Pelos perigos que corre uma água pura, uma água cristalina, pode-se medir o fervor com o qual acolhemos, em seu frescor e juventude, o riacho, a fonte, o rio, toda essa reserva da limpidez natural. Sentimos que as metáforas da limpidez e do frescor têm uma vida assegurada quando se ligam a realidades tão diretamente valorizadas. (Bachelard, 1997, p. 144).

Ao se pensar em ambos os rios, seja em Luciano Serafim seja em Guimarães Rosa, enquanto espacialidades do "entre", enquanto metáfora da fronteira, enquanto "meio" que remete ao centro, mesmo sendo margem, por baixo dessa limpidez natural, da água cristalina, tem-se uma obscuridade dúbia que reflete o íntimo do ser e, simultaneamente, representa a (terceira) margem, para além da superficialidade.

Por fim, como o personagem rosiano, que apareceu "aí e lá, o vulto", assim configura-se o personagem de Serafim, quando, no fim, joga-se no rio e passa a situar-se neste lugar não-encontrável, retornando à sua origem.

\section{CONSIDERAÇÕES FINAIS}

Verifica-se, na relação das margens, entre Luciano Serafim (2003) e Guimarães Rosa (2001) - seja nas espacialidades ambientadas em ambos os contos, seja no confronto dos lugares de enunciação literária, representados pelos autores em destaque -, que produções literárias com tais características, por muito tempo foram e ainda são chanceladas pela teoria e pela crítica literária eurocêntricas, como uma espécie de subliteratura, recebendo a alcunha de regionais e/ou marginais.

Wladimir Krysinski (2005), contribui para esses apontamentos finais, ao abordar questões inerentes a uma literatura mundo, uma literatura una, ideal, bem como ao elucidar as literaturas pós-coloniais e a forma como elas passam fortalecer a ideia de uma literatura poliglota, uma literatura transnacional e, consequentemente, antagônica, cujo valor é reconhecido internacionalmente, forçando, assim, o estilhaçamento dos grandes cânones.

Este é outro desafio da(s) periferia(s) contra o eurocentrismo e seu discurso hegemônico, em certa medida ainda vigente - a "questão do cânone. Questionar "um sistema de valores instituído por grupos detentores de poder, que legitimam decisões particulares com um discurso globalizante" (Coutinho, 2008, p. 24), torna-se fundamental para se abrir espaço nacional e internacionalmente a obras produzidas nas/pelas margens, mas 
não menos robustas em termos de temas e conteúdo, não menos consistentes esteticamente, tampouco menos importantes que as grandes obras já estabelecidas. Isso vale para o universo literário sul-mato-grossense, o qual inscreve-se nesse processo de afirmação e reconhecimento na busca por uma identidade, bem como para a expressão literária de Luciano Serafim: autor capaz de, por meio de sua literatura, elevar a noção de margem, atribuindo a ela uma carga semântica menos pejorativa; mais que isso, capaz de olhar no seu entorno e ver as margens em um não-lugar, em um espaço a ser visitado e (re)visto; logo, capaz de representar o aprendizado do ser humano com as águas que gritam silenciosamente a quem deseja ouvir.

Finalizo sob a condição de vivente de um (não-)lugar habitado por escritores, poetas e artistas, conscientes do papel que exercem para uma construção cultural na qual estão inscritos. Assim, reitero os questionamentos de Hugo Achugar (2006), o que ainda permanece é a pergunta pela identidade: quem somos? O que nos diferencia? O que nos identifica? Tais indagações valem tanto se pensarmos a partir do locus enunciativo dos escritores quanto da perspectiva dos personagens situados nesses não-lugares, às margens.

\section{REFERÊNCIAS BIBLIOGRÁFICA}

ACHUGAR, Hugo. Planetas sem boca: escritos efêmeros sobre arte, cultura e literatura. Trad. Lyslei Nascimento. Belo Horizonte: Editora UFMG, 2006, p. 81-101.

BACHELARD, Gaston. A água e os sonhos: ensaio sobre a imaginação da matéria. Tradução de Antônio de Pádua Danesi. São Paulo: Martins Fontes, 1997.

BACHELARD, Gaston. A poética do espaço. Tradução de Antônio de Pádua Danesi. 2a ed. - São Paulo: Martins Fontes, 2008, p. 189-214.

BOURDIEU, Pierre. O Poder Simbólico. "A Identidade e a Representação - elementos para uma reflexão crítica sobre a ideia de região" (cap. 5). Tradução Fernando Tomaz (Português de Portugal) 16ª ed. Rio de Janeiro: Bertrand Brasil, 2012.

BRAIT, Beth. Guimarães Rosa: seleção de textos, notas, estudos biográfico, histórico e crítico e exercícios por Beth Brait. São Paulo: Abril Educação, 1982.

CARVALHAL, Tânia Franco. "Comunidades inter-literárias e relações entre literaturas de fronteira”. In: Identidade \& representação. (Org.) Raúl Antelo. Florianópolis, UFSC, 1994.

CHARAUDEAU, Patrick; MAINGUENEAU, Dominique. Dicionário de análise do discurso. Coordenação da tradução Fabiana Komesu. $2^{\mathrm{a}}$ ed., $1^{\text {a }}$ reimpressão. São Paulo, Contexto, 2008, p. 220-221.

CHEVALIER, Jean. Diccionário de los siímbolos. Colaboración de Alain Gheerbrant. Barcelona. Editorial Herder, 1986. 
COUTINHO, F. Eduardo. "A literatura comparada e o contexto latino americano”. In: Raído, Dourados, MS, v. 2, n. 3, jan./jun. 2008, p. 21-31.

FIGUEIREDO, Eurídice. Literatura comparada: o regional, o nacional e o transnacional. Revista Brasileira de Literatura Comparada / Associação Brasileira de Literatura Comparada. Rio de Janeiro: Abralic, v.15, n.23, p. 31-43, 2013.

KALIMAN, Ricardo. La palabra que produce regiones. El concepto de region desde la teoria literaria. Tucuman: Universidad Nacional del Tucumán, Faculdad del Filosofia y Letras, Instituto de Historia y Pensamiento Argentinos, Julio, 1994.

KRYSINSKI, Wladimir. "Narrativa de valores: os novos actantes da Weltliteratur". In: Revista Brasileira de Literatura Comparada / Associação Brasileira de Literatura Comparada n. 7, 2005, p. 193-205.

NOLASCO, Edgar C. Para onde devem voar os pássaros depois do último céu? In: Raído. Revista do Programa de Pós-Graduação em Letras da UFGD. Dourados MS, UFGD, v. 2, n. 3, 2008, p. 65-76.

POZENATO, José Clemente. O Regional e o Universal na Literatura Gaúcha. Porto Alegre: Ed. Movimento, Instituto Estadual do Livro, 1974.

ROSA, João Guimarães. Primeiras estórias. Rio de Janeiro: Nova Fronteira, 2001.

SANTIAGO, Silviano. "O entre-lugar do discurso latino-americano". In: _. Uma literatura nos trópicos: ensaios sobre dependência cultural. $2^{\circ}$ ed. Rio de Janeiro: Rocco, 2000. p. 9-27.

SANTOS, Paulo Sérgio Nolasco dos. Fronteiras do Local: roteiro para uma leitura crítica do regional sul-mato-grossense. Paulo Sérgio Nolasco dos Santos. Campo Grande, MS : Ed. UFMS, 2008, p. 9-40.

SANTOS, Paulo Sérgio Nolasco dos. "Situação crítica: o regionalismo revisitado" In: Literatura e Práticas Culturais. Paulo Sérgio Nolasco dos Santos (org.). Dourados, MS : UFGD, 2009, p. 75-109. Disponível em: < http://200.129.209.183/arquivos/arquivos/78/EDITORA/catalogo/literatura-e-praticas-culturais-nolasco-paulo-org.pdf > Acesso em: 04/05/2017.

SERAFIM, Luciano. Outro dia a gente sai. Contos brasileiros. Dourados: Grupo literário Arandu, 2003.

SERAFIM, Luciano. Eu entre nós. Dourados: Semact - FIC/MS, 2002.

SERAFIM, Luciano. Raiz transeunte. Dourados: Arrebol Coletivo Literário, 2013.

SOUZA, Eneida Maria de. Crítica cultural em ritmo latino. In: . Tempo de Pós-Crítica: ensaios. 2. Ed. Belo Horizonte: Veredas \& Cenários, 2012, p. 145-156.

SOUZA, Eneida Maria de. Pós-teorias. In: GONÇALVES, Ana B.; CARRIZO, Silvina L.; LAGE, Verônica L. (org.). Literatura, crítica, cultura. Juiz de Fora: Editora UFJF. 2009, p. 223-221.

SOUZA, Eneida Maria de. Saberes Narrativos. Scripta. Belo Horizonte, v. 7, n. 14, p. 56-66, $1^{\circ}$ sem. 2004. Disponível em: < http://www.ich. 
pucminas.br/cespuc/Revistas_Scripta/Scripta14/Conteudo/N14_Parte01_ art05.pdf . > Acesso em: 26/06/2016.

SOUZA, Eneida Maria de. O fim das ilusões. In: Tempo de Pós-crítica: ensaios. 2. Ed. Belo Horizonte: Veredas \& Cenários, 2012, p. 133-144.

\section{Recebido para publicação em 02/05/2018 \\ Aprovado em 07/09/2018}

\section{NOTAS}

1 Mestrando em Literatura e Práticas Culturais (UFGD/CAPES), Especialista em Estudos Literários (UEMS) e Graduado em Letras Português-Inglês (UFGD). E-mail: cristian.aristoly@hotmail.com.

2 Mestra em Letras (UFGD). Atualmente é Professora Convidada no curso de Pós-Graduação em Letras (UEMS-Dourados).E-mail: deborasimoes@uems.br.

3 Ver preceitos de Paul Ricoeur, postulados em Tempo e narrativa.

4 Este conceito suscitado por Silviano Santiago, nos orienta "para bem precisar a situação e o papel do escritor latino-americano, vivendo entre a assimilação do modelo original, isto é, entre o amor e o respeito pelo já escrito, e a necessidade de produzir um novo texto que afronte o primeiro e muitas vezes o negue”. (Santiago, 2000, p. 23).

5 Ver conceitos em Histórias locais/Projetos globais: colonialidade, saberes subalternos e pensamento liminar, de Walter Mignolo.

6 “Termo emprestado da retórica antiga, o ethos (em grego, personagem) designa a imagem de si que o locutor constrói em seu discurso para exercer uma influência sobre seu alocutário. Essa noção foi retomada em ciências da linguagem e, principalmente, em análise do discurso, em que se refere às modalidades verbais da apresentação de si na interação verbal”. Cf. Dicionário de Análise do Discurso, 2008, p. 220.

7 "O regional se opõe ao nacional enquanto critério externo de demarcação de um corpus literário, de preferência apoiado em bases culturais. O regional, em oposição ao universal, é uma forma do particular, e deve ser subsumido por este último termo, que caracteriza um dos elementos do processo metonímico que leva, do particular ao universal, o sentido de um determinado universo literário." (Pozenato, 1974, 17).

8 Com base em estudos publicados em periódicos, bancos de dissertações e teses da área dos estudos literários.

9 Editora cartonera dedicada a autores sul-mato-grossenses, com 15 títulos lançados até o momento da publicação deste artigo.

10 "no Mundaú/ lavamos/ roupas/ mas/ não limpamos/ a alma//[...]/ pela ponte/ passa/ carreta com cana/ caminhonete/ carro de boi/ boiada/ embaixo, escorrem/ peixes jangadas/ sabão em pó/ água sanitária/ cadáver baleado [...]” (Serafim, 2013, p. 51). Poesia de Luciano Serafim fazendo referência ao rio Mundaú, um dos elementos de "A outra margem".

11 Não custa lembrar que há muitos outros pontos altos na vida e na produção literária de Guimarães Rosa, já conhecido por muitos, dentre estes a publicação de sua grande obra: Grande Sertão: veredas. Para consulta completa das obras do autor e da cronologia biográfica: Cf. BRAIT, Beth. Guimarães Rosa: seleção de textos, notas, estudos biográfico, histórico e crítico e exercícios por Beth Brait. - São Paulo: Abril Educação, 1982.

12 Faz-se relevante mencionar, dada a sua importância para a cultura brasileira, que o conto em destaque virou música e filme, com a parceria de Milton Nascimento / Caetano Veloso, no álbum Circuladô (1991) e Nelson Pereira dos Santos (1994), respectivamente. Ambos com o mesmo título do conto.

13 Traduzido do espanhol: "El agua es el símbolo de las energías inconscientes, de las potencias informes del alma, de las motivaciones secretas y sconocidas". Cf.: CHEVALIER, Jean. Diccionário de los símbolos. Colaboración de Alain Gheerbrant. Barcelona. - Editorial Herder, 1986.

14 Cf.: Álbum Circuladô (1991; grifo nosso). 